\title{
Analysis of Various Types Engineering Stripe Knit Fabrics of Bangladeshi Knit Industry
}

\author{
Gazi Farhan Ishraque Toki1,2* ${ }^{\circledR}$, Sumonta Ghosh1, Rezaul Karim Khan Alave1, \\ Dibakor Chatterjee1, Tahsina Islam Chhoa', Ummor Sahadat Mrs. Fahmin Sultana Snigdha1 \\ ${ }^{1}$ Department of Textile Engineering, National Institute of Textile Engineering and Research (NITER), Dhaka, Bangladesh \\ ${ }^{2}$ Department of Material Precession Engineering, Donghua University, Shanghai, China \\ Email: *gazifarhanishraquetoki@gmail.com
}

How to cite this paper: Toki, G.F.I., Ghosh, S, Alave, R.K.K., Chatterjee, D., Chhoa, T.I. and Snigdha, U.S.M.F.S. (2021) Analysis of Various Types Engineering Stripe Knit Fabrics of Bangladeshi Knit Industry. Journal of Textile Science and Technology, 7, 161171

https://doi.org/10.4236/jtst.2021.74014

Received: September 16, 2021

Accepted: November 5, 2021

Published: November 8, 2021

Copyright $\odot 2021$ by author(s) and Scientific Research Publishing Inc. This work is licensed under the Creative Commons Attribution International License (CC BY 4.0).

http://creativecommons.org/licenses/by/4.0/

\begin{abstract}
This experiment is generally based on the three types of engineering stripe fabrics named single jersey, full feeder lycra single jersey, and single lacoste fabric. In Bangladesh, conventional practices of engineering stripe fabric hardly seen. As the textile engineer, we focused to identify the basic difference between these fabrics. We kept the repeat length constant for all three fabrics. In these circumstances, how stitch length, yarn count, gsm, fabric dia, machine settings, machine maintenance, machine rpm varies into those three mentioned fabrics. It is the main motto of these experiments to make them more favourable into the trendy fashion world.
\end{abstract}

\section{Keywords}

Engineering Stripe, Fingers, Semi-Positive Feeder, Knit Fabric, Six Colours

\section{Introduction}

Generally, the horizontal-coloured stripe designs are produced in course wise direction. According to the stripe design, there are two types of stripe fabrics:

A. Feeder stripe fabric: When maximum "2 - 3" colours are used to knit a stripe fabric where the stripe pattern length is lower than it is called feeder stripe (Figure 1). The feeder stripe designs are knitted on the general circular knitting machine. The main principle is to feed " 2 - 3 " colours on the feeders according to design and let the machine knit the required design. The knitting machine has a capacity for 108 cones of yarn. If you have inserted 8 black yarns to the feeder, with 100 cones of white yarn next. When knitting starts, you will see within the 2 inches repeat there is a black and white horizontal stripe. Feeder stripe designs can be made on Single jersey, Rib and Interlock machines. 


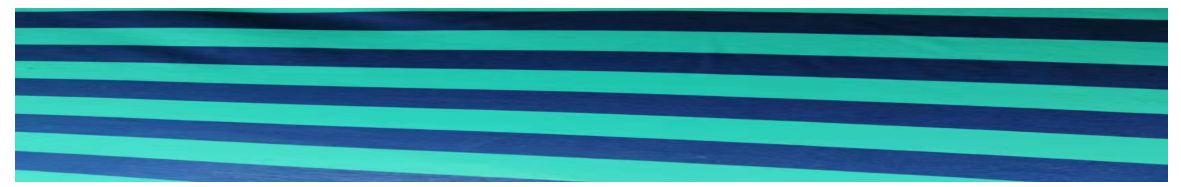

Figure 1. Feeder stripe single jersey fabric.

B. Engineering stripe: When the size of the stripe repeat of the fabric is bigger than 2 inches which is beyond what the feeder stripe method can do, it is called engineering stripe. Engineering stripe designs are produced on a special type of circular knitting machine named auto stripe/engineering stripe machine. In the engineered stripe method, the machine is set to change threads at a certain time from a big repeat. This way the repeat can be of almost any size. However, the price of engineered stripe fabric is substantially higher.

It is produced in a special type of machine usually with four or six fingers arrangement called Auto Striper or Engineering Striper Machine. This type of machine was introduced to increase the scope of striping. The selection of each striping finger is affected by a programmable microcomputer in which the design information is fed. Solenoids above each striping finger are used to transmit striping instruction in accordance with the programme. It has an individual trapping and cutting of yarn at each finger.

The auto striper machine is equipped with a striper device called finger. The machine has usually 3, 4 or 6 fingers against each feeder. The fingers are centrally controlled either by a chain switch apparatus and rotating switch cams, or with the help of an electrical pre-selection and a mechanical rotary switch [1] [2].

For six colours engineering stripe, it's very rare to find the same repeat length of various fabrics like single jersey, full feeder lycra single jersey, single lacoste fabrics. Our aim is to make sure that how those fabrics GSM, stitch length varies along with yarn count. That's why we fixed how many courses would need for those respective fabrics to get the same numbers of repeat length.

In this experiment, we also investigated how stitch length, yarn count, yarn tension, machine rpm affects the fabric properties during production. Machine settings and proper maintenance before and after production is also a big factor during this experiment. Operation settings are also a big influential factor in this experiment.

In Bangladesh, most of the industries rarely practice these sorts of fabrics due to lack of orders. It is high time that we should enlist it priority to make acknowledgement of diversity into the fashion world through this kind of fabric.

\section{Machine Specification}

Engineering stripe single jersey knitting machine: This mentioned specified machine is used for the experiment.

\begin{tabular}{cc}
\hline Brand name & Pailung \\
\hline Origin & Taiwan \\
\hline
\end{tabular}




\section{Continued}

\begin{tabular}{cc}
\hline Diameter of the machine & 30 inches \\
Machine gauge & 24 \\
No. of feeder & 42 \\
No. of colours/No. of fingers & 6 \\
No. of needles & 2256 pieces \\
\hline
\end{tabular}

Engineering stripe yarn path diagram: For the experiment, we need to concentrate into machine yarn path diagram of the followings:

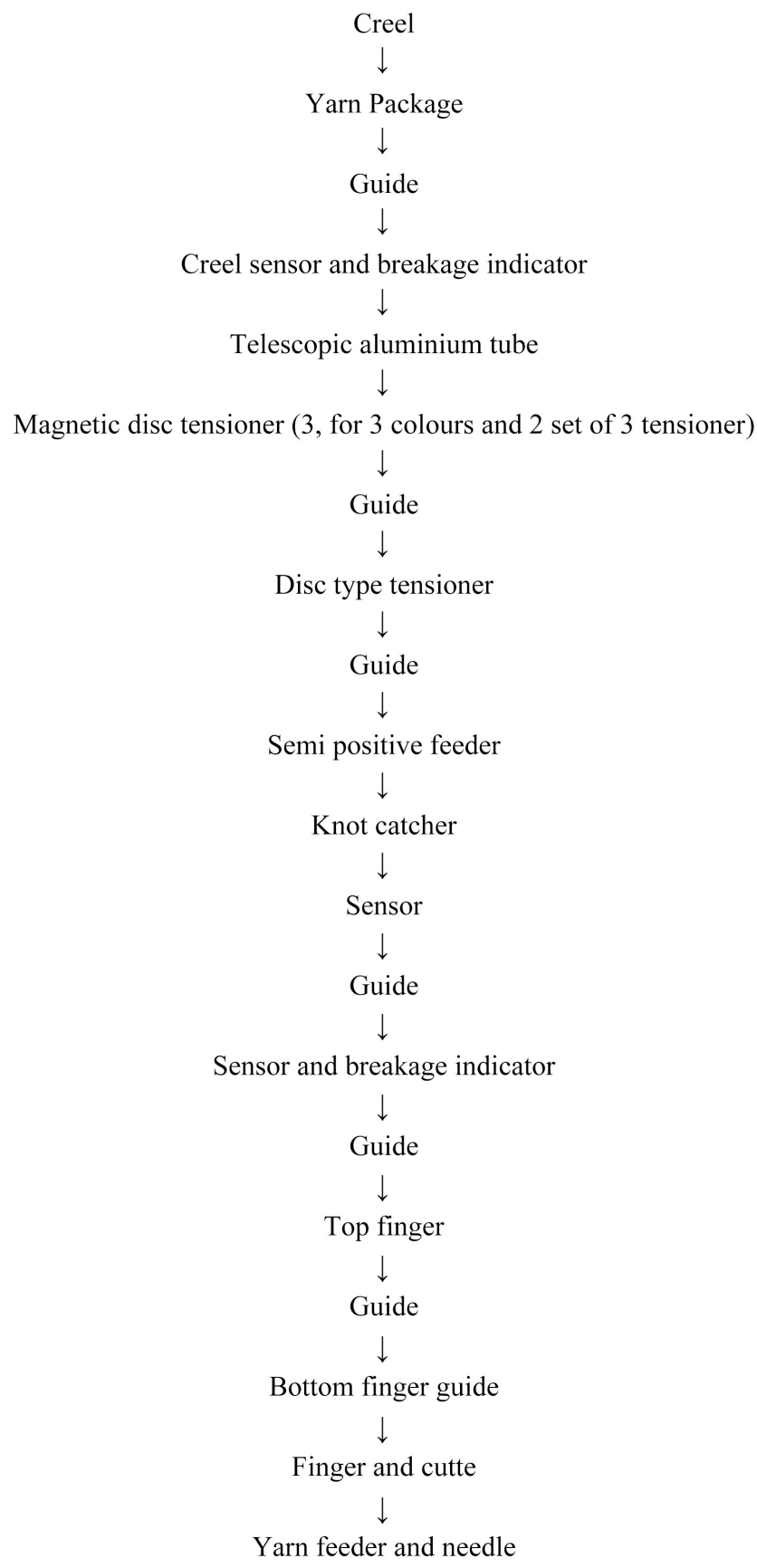




\section{Additional Parts of Engineering Stripe Knitting Machine}

- Creel stop motion - Semi-Positive feeder • Lycra yarn feeder • Additional tensioners • Finger • Finger box • Cutter • Actuator • Swing cam system.

Semi-positive feeder: Engineering Stripe machines have semi-positive yarn feeders (Figure 2). The thread path is given below [1] [2]:

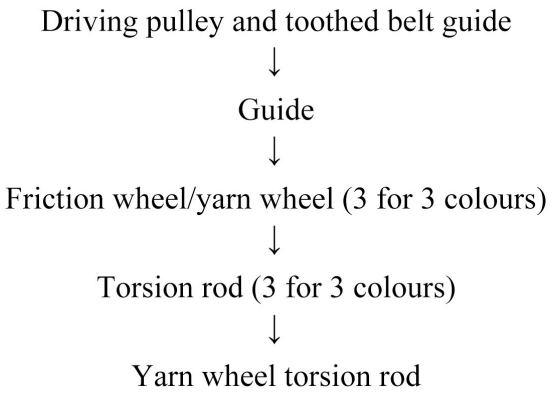

Feeding principle: The striper feeder is based on the friction principle. The income yarn is guided through ceramic eyelets and a torsion rod and wound around the feed wheel for 1 - 2 circles. For 6 finger $\mathrm{m} / \mathrm{c}$, there are 2 feeding devices with 3 yarn wheels. These yarn feeders present torsion rod. By means of the friction between yarn and the wheel, the striper feeder provides a reliable yarn transport. Whenever a yarn is selected, it twists and moves away from wheel and thus gives sufficient tension for feeding. Other deselected rods remain close to wheel and where yarn tension is lower [3].

Finger: The yarn is fed with the help of finger motion. There are " 4 - 6" fingers against each feeder. The finger works with the help of actuator. Selection of each finger is affected from control panel in which the design is fed. It has an individual clamping and cutting of yarn at each finger (Figure 3) [4] [5].

Finger box: All the fingers are attached in a box. For 4 fingers there are 4 metallic butts below of every finger box. The actuator selectors beat one of the fingers but to make it active (Figure 4).

Piezoelectric data actuator: An electronic actuator activates the powerful yet swift mechanical movement of finger in yarn change. The actuator has " 4 - 6" selectors for four to six finger machines. The actuator is situated below the finger box and rotated with cylinder rpm. For 6 finger machine, 5 selectors will beat the 5 finger box butts. These 5 fingers will disable, only one finger will active. This one finger will take the selected thread. According to the program predetermined courses will be formed. Thus, another predetermined course will form (Figure 5).

\section{Additional Features of Engineering Stripe Machine}

Control panel for engineering stripe: Data acquisition system for machine control, recording and displaying the machine functions. Controller with $8 \mathrm{MB}$ memory capacity and easy to select coloured yarn by means of the control panel, it is easy to change or select a coloured yarn, and modifies the stripe width. Error messages are shown on the display and can quickly be localized [1]. 


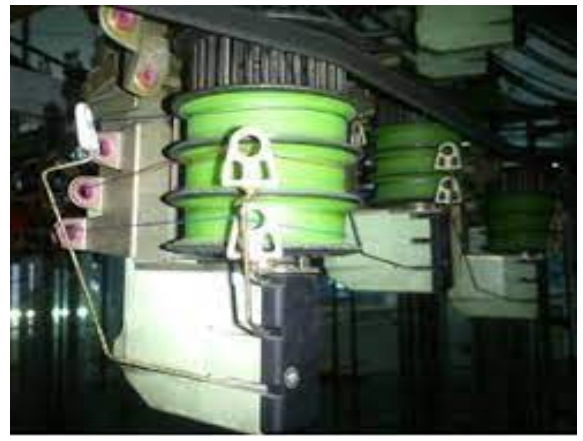

Figure 2. Semi-positive feeder.

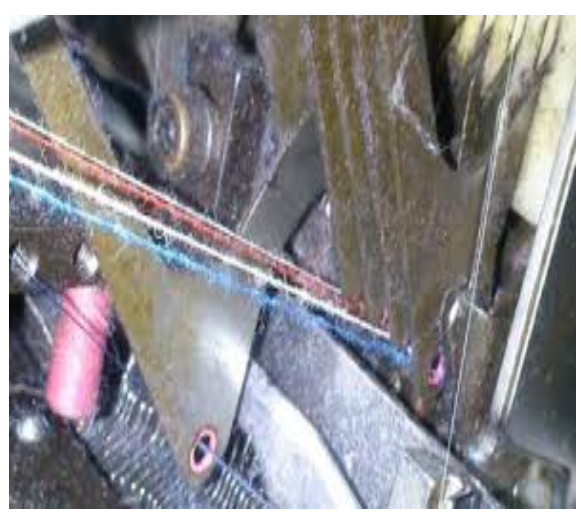

Figure 3. Four finger machine.

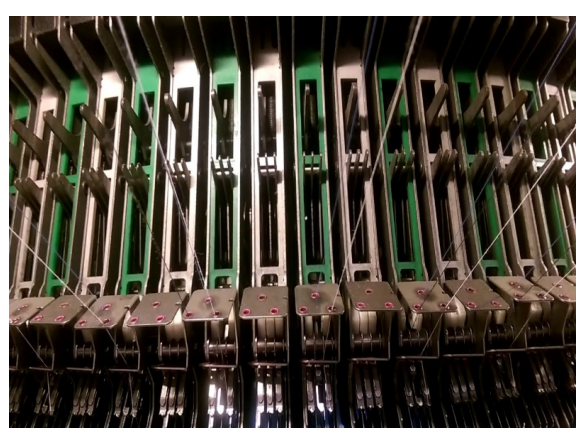

Figure 4. Finger box.

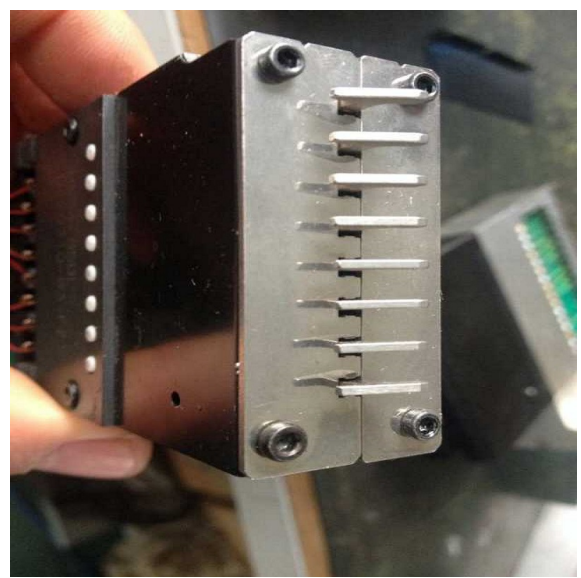

Figure 5. Actuator. 
Design control system: The pattern data input through LCD touch panel. The computer program controls the changing for 4 or 6 colours striper fabric. With memory function, the computer control thread adjustment system can control many colour threads and can type:

1) Colour No.

2) Stripe No.

3) Course No. as you required [4] [5] [6].

Interchange ability: A quick-response actuator enables electronic selection at high speed. It can knit with various single knit structures such as Jersey, Pique, Lacoste, Terry as well as $1 \times 1$ Rib and $1 \times 1$ Interlock, etc [5] [7].

Durable and vertical mount fingers: The striper fingers are designed with independent yarn cutter with cancellation function. It is vertically mount for highest productivity, for easy maintenance. 4-colour and 6-colour stripers are built from similar platform and principles. They are used on both Single Jersey and Double Jersey machines [5] [8] [9].

Easy patterning software: It facilitates user in designing creative patterns. For greatest convenience of user, the patterns can be edited at the machine via the striper control panel [1] [10].

Engineering stripe machine set-up process [pailung]:

Step 1: Initially a new file is started, or previously available file is opened.

Step 2: Than a particular file no. is selected which is selected from an external device (pen drive) or an available file for editing. After touching ENT, it will skip to finger touch specification.

Step 3: Edited total numbers of courses and press ENT for the full pattern into the monitor.

Step 4: Edited total numbers of pattern and press ENT key.

Step 5: For 1st stripe of the pattern total no. of course is edited and press ENT.

Step 6: Now for every single stripe of the pattern the yarn colour is selected as A, B, C based on finger, edited, press ENT and later confirm the finger specification.

Step 7: Follow step-6 for the remaining stripes of the pattern.

Step 8: After entering the repeat, the folder has to be saved. Finally, the finger will work according to the program as provided into the monitor.

Knitting operation:

- The control panel sends control pulses to the actuator for the yarn insertion of selected yarn.

- There is a butt below every finger box.

- An actuator selector disconnects other butts and only one finger of finger box is selected.

- Actuator selects the finger according to the control panel command.

- There is a cutter with every finger box that cuts yarn after the completion of a course.

- The insertion process is implemented mechanically by means of cams. 
- Optimally designed transmission ensures accurate insertion, clamping and cutting of the yarn, even at high machine working speeds [1] [11] [12].

\section{Yarn changing process through finger:}

Figure gives the aspect of a 4 fingers striper. We can see that the finger 1 is being selected and the finger 4 is being deselected. A cutting blade cuts the deselected yarn. Yarn change occurs in small zone (about $7 \mathrm{~cm}$ width) because in this zone 2 yarns work simultaneously during yarn change (Figure 6) [1] [13] [14] [15].

\section{Results \& Discussion}

\section{Case study 1:}

Fabric specification:

Name: Engineering stripe normal single jersey;

Order: Development sample;

Finish día: Needle open;

Finish gsm: 180;

Stitch length: 2.95;

Yarn count: $22 \mathrm{Ne}$.

Cam arrangement:

\begin{tabular}{llll}
\hline $\mathrm{K}$ & $\mathrm{K}$ & $\mathrm{K}$ & $\mathrm{K}$ \\
$\mathrm{K}$ & $\mathrm{K}$ & $\mathrm{K}$ & $\mathrm{K}$ \\
\hline
\end{tabular}

Here, Cam arrangement " $K$ " indicates Knit Cam (for 1 \& 2 butt needle).

From Table 1 found that, in six finger engineering stripe machines, in this development we initially installed the needle for engineering stripe single jersey fabric. As it used same amount length for each repeat which measured in centimetre $(\mathrm{cm})$. In comparison with the other two developments, single jersey fabric consumed less revolution (Figure 7).

\section{Case study 2:}

Fabric specification:

Name: Engineering stripe full feeder single jersey;

Order: Development sample;

Finish dia: Knife open;

Finish gsm: 230;

Stitch length: 3.30 ;

Yarn count: $30 \mathrm{Ne}$;

Lycra count: 40 denier;

Lycra\%: 8\% (268 cm).

Cam Arrangement:

\begin{tabular}{llll}
\hline $\mathrm{K}$ & $\mathrm{K}$ & $\mathrm{K}$ & $\mathrm{K}$ \\
$\mathrm{K}$ & $\mathrm{K}$ & $\mathrm{K}$ & $\mathrm{K}$ \\
\hline
\end{tabular}

Here, Cam arrangement "K" indicates Knit Cam (for $1 \& 2$ butt needle). 


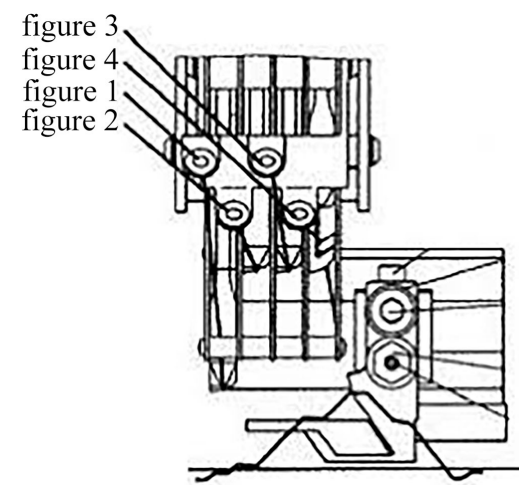

Figure 6. Yarn from finger to needle.

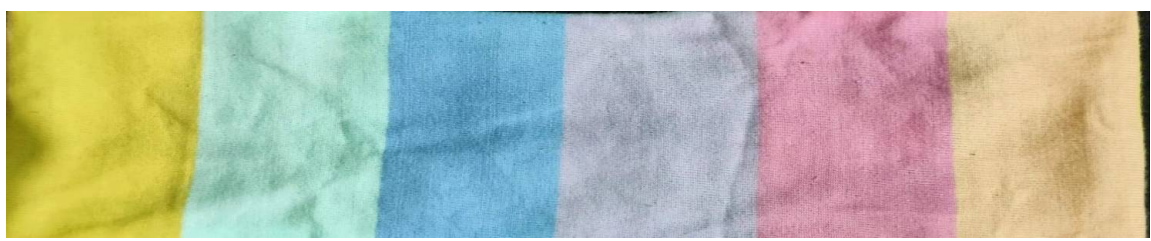

Figure 7. Engineering stripe single jersey (6 Colours).

Table 1. Individual colour selection for engineering stripe single jersey fabric (6 Colours).

\begin{tabular}{cccccc}
\hline Serial & Colour & Courses & Sequences & Finger & CM \\
\hline 1 & $15-3920$ TCX & 83 & $1-42 ; 1-41$ & A & 4.6 \\
2 & $12-5206$ TCX & 83 & $1-42 ; 1-41$ & D & 4.6 \\
3 & $12-0736$ TCX & 83 & $1-42 ; 1-41$ & E & 4.6 \\
4 & $13-1023$ TCX & 83 & $1-42 ; 1-41$ & C & 4.6 \\
5 & $15-2216$ TCX & 83 & $1-42 ; 1-41$ & B & 4.6 \\
6 & $14-3612$ TCX & 83 & $1-42 ; 1-41$ & F & 4.6 \\
& Total & 498 & & Total & 27.6 \\
\hline
\end{tabular}

From Table 2 found that, in six finger engineering stripe machines, in this development we exchange installed needle for engineering stripe full feeder lycra single jersey fabric. In comparison with the other two developments, single jersey lycra fabric consumed much more revolution than other two fabric because of its lycra consumption. Before lycra adjustment, lycra instalment and lycra $\mathrm{cm}$ adjustment is also followed properly. Otherwise lycra drop, lycra cotton, lycra out problem could breakout simultaneously (Figure 8).

\section{Case study 3:}

\section{Fabric specification:}

Name: Engineering stripe single lacoste;

Order: Development sample

Finish día: Knife open;

Finish gsm: 160;

Stitch length: 2.85;

Yarn count: $22 \mathrm{Ne}$. 
Table 2. Individual colour selection for engineering stripe full feeder lycra single jersey fabric (6 Colours).

\begin{tabular}{cccccc}
\hline Serial & Colour & Courses & Sequences & Finger & CM \\
\hline 1 & $15-3920$ TCX & 101 & $1-42 ; 1-42,1-17$ & $\mathrm{~A}$ & 4.6 \\
2 & $12-5206$ TCX & 101 & $1-42 ; 1-42,1-17$ & $\mathrm{~B}$ & 4.6 \\
3 & $12-0736 \mathrm{TCX}$ & 101 & $1-42 ; 1-42,1-17$ & $\mathrm{C}$ & 4.6 \\
4 & $13-1023 \mathrm{TCX}$ & 101 & $1-42 ; 1-42,1-17$ & $\mathrm{D}$ & 4.6 \\
5 & $15-2216 \mathrm{TCX}$ & 101 & $1-42 ; 1-42,1-17$ & $\mathrm{E}$ & 4.6 \\
6 & $14-3612 \mathrm{TCX}$ & 101 & $1-42 ; 1-42,1-17$ & $\mathrm{~F}$ & 4.6 \\
& Total & 606 & $1-42 ; 1-42,1-17$ & Total & 27.6 \\
\hline
\end{tabular}

Table 3. Individual colour selection for engineering stripe single lacoste fabric (6 Colours).

\begin{tabular}{cccccc}
\hline Serial & Colour & Courses & Sequences & Finger & CM \\
\hline 1 & $15-3920$ TCX & 98 & $1-42 ; 1-42,1-14$ & $\mathrm{~A}$ & 4.6 \\
2 & $12-5206$ TCX & 98 & $1-42 ; 1-42,1-14$ & $\mathrm{~B}$ & 4.6 \\
3 & $12-0736$ TCX & 98 & $1-42 ; 1-42,1-14$ & $\mathrm{~F}$ & 4.6 \\
4 & $13-1023$ TCX & 98 & $1-42 ; 1-42,1-14$ & $\mathrm{C}$ & 4.6 \\
5 & $15-2216$ TCX & 98 & $1-42 ; 1-42,1-14$ & $\mathrm{D}$ & 4.6 \\
6 & $14-3612$ TCX & 98 & $1-42 ; 1-42,1-14$ & E & 4.6 \\
& Total & 588 & & Total & 27.6 \\
\hline
\end{tabular}

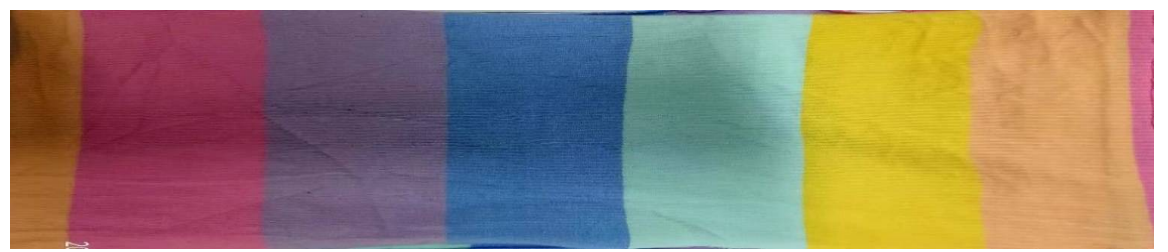

Figure 8. Engineering stripe full feeder lycra single jersey (6 Colours).

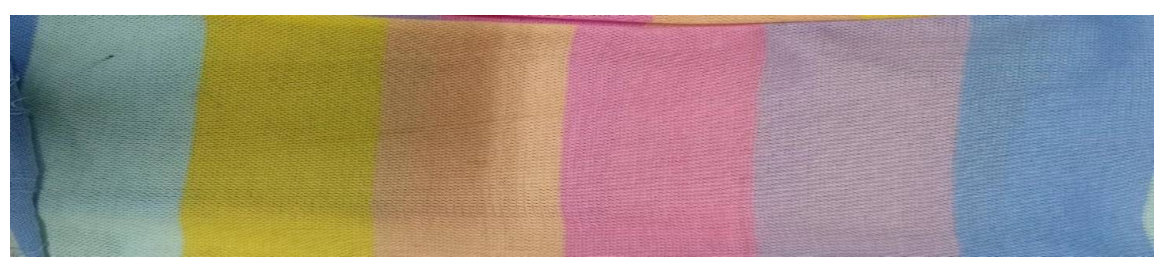

Figure 9. Engineering stripe single lacoste (6 Colours).

\section{Cam arrangement:}

\begin{tabular}{llll}
\hline $\mathrm{T}$ & $\mathrm{K}$ & $\mathrm{T}$ & $\mathrm{K}$ \\
$\mathrm{K}$ & $\mathrm{K}$ & $\mathrm{K}$ & $\mathrm{K}$ \\
\hline
\end{tabular}

Here, Cam arrangement " $\mathrm{K}$ " and " $\mathrm{T}$ " indicates Tuck and Knit Cam respectively (for 1 and 2 butt needle). 
From Table 3 found that, in six finger engineering stripe machines, in this development we again installed the needle as like engineering stripe single jersey fabric. In comparison with other two developments, single jersey lacoste fabric consumed less revolution than lycra fabric and more than single jersey fabric. After needle installation cam arrangement need to be done (Figure 9).

\section{Conclusion}

In comparison, with other engineering stripe fabrics, 6 colours combo fabric is less produced in the knit industry of Bangladesh. In this experiment, we produced three different fabrics which have contained the same length of the repeat. But from fabric to fabric, the number of courses and gsm varies along with stitch length, yarn count, fabric dia, etc. Machine maintenance is also a big criterion during this experiment.

\section{Future Scope}

- Machine parameters should be investigated for more improvement;

- Software development for more added colours;

- To increase production efficiency.

\section{Conflicts of Interest}

The authors declare no conflicts of interest regarding the publication of this paper.

\section{References}

[1] Ahmed, S. (2018) Comparative Study between Engineering Stripe and Feeder Stripe. Journal of Textile Science and Engineering, 8, 2.

[2] Saha, J.K. (2015) A Comprehensive Study of Engineering Stripe Design on Auto Striper Single Jersey Knitting Machine Production. International Journal of Fashion Design Technology and Education, 5, 7-14.

[3] LISKY Circular Knitting Machine. https://www.liskytech.com/

[4] Ahmed, F., Hossain, M.I., Ahmed, A.F. and Ahmed, D.M. (2018) Development of Software for the Adjustment of Maximum Color Variation in Auto Striped Knit Fabric.

[5] Feeder Stripe, Auto Stripe, Engineering Stripe. https://www.slideshare.net/nazmul shuvo/feeder-stripe-auto-stripe-engineering-str ipe

[6] Toki, G.F.I., Banik, A., Ahmed, T., Mia, R., Alave, R.K.K., Jahan, J., Palash, M.M.R. and Farsee, M.S. (2021) Developing Denim Like Wash Effect on Corduroy Garments and Investigation of Different Physical Properties of Washed Corduroy Garments. Journal of Textile Science and Technology, 7, 1. https://doi.org/10.4236/jtst.2021.71001

[7] Shogofurov, S., Kamalova, I. and Xolikov, K. (2021) Study of the Effect of Changes on the Technological and Physical-Mechanical Properties of Knitting in a New Structure. Engineering, 13, 287-299. https://doi.org/10.4236/eng.2021.136021

[8] Anbumani, N. (2007) Knitting Fundamentals, Machines, Structures and Developments. New Age International (P) Ltd., New Delhi. 
[9] Spencer, D.J. (1989) Knitting Technology. Woodhead Publishing Limited, Sawston.

[10] Belal, S.A. (2009) Understanding Textiles for a Merchandiser. BMN3 Foundation, Dha$\mathrm{ka}$.

[11] Abdessalem, S.B. (n.d.) Elements of Circular Knitting Machines. National Geographic Society, Washington DC, 9-10.

[12] Iyer, C., Mammel, B. and Schach, W. (1992) Circular Knitting. Meisenbach GmbH, Bamberg, 126-128.

[13] Nizam, E.H. (2015) A Comprehensive Study of Engineering Stripe Design on Auto Stripper Single Jersey Knitting Machine Production. International Journal of Fashion Design Technology and Education, 5, 7-14.

[14] Feeder Stripe, Engineering Stripe and Auto Stripe Mechanism. http://www.slideshare.net/88azmir/feeder-stripe-engineering-stripe-and-auto-stripe -mechanism

[15] What Are Difference between Feeder Stripe and Engineering Stripe? https://textilestudy365.blogspot.com/2017/05/difference-between-feeder-stripe-and -engineering-stripe.html 